\title{
Thrombolytic Therapy in Patients Requiring Cardiopulmonary Resuscitation
}

Alan N. Tenaglia, MD, Robert M. Califf, MD, Richard J. Candela, MD, Dean J. Kereiakes, MD, Eric Berrios, RN, Sharon Y. Young, MS, Richard S. Stack, MD, and Eric J. Topol, MD

Cardiopulmonary resuscitation (CPR) is often considered a contraindication to thrombolytic therapy for acute myocardial infarction. of 708 patients involved in the first 3 Thrombolysis and Angioplasty in Myocardial Infarction trials of lytic therapy for acute infarction, 59 patients required $<\mathbf{1 0}$ minutes of CPR before receiving lytic therapy (CPR >10 minutes was an exclusion of the trials) or required CPR within 6 hours of treatment. The patients receiving CPR were simflar to the remainder of the group with respect to baseline demographics. The indication for CPR was usually ventricular fibrillation (73\%) or ventricular tachycardia (24\%). The median duration of CPR was 1 minute, with twenty-fifth and seventy-fifth percentiles of 1 and 5 minutes, respectively. The median number of cardioversions/defibrillations performed was 2 (twenty-fifth and seventy-fifth percentiles of 1 and 3 minutes, respectively). Patients receiving CPR were more Hkely to have anterior infarctions (66 vs $39 \%$ ), the left anterior descending artery as the infarctrelated artery (63 vs $38 \%$ ) and lower ejection fractions on the initial ventriculogram $(46 \pm 11$ vs $52 \pm 12 \%$ ) than those not receiving CPR. Inhospital mortality was 12 vs $6 \%$ with most deaths due to pump failure (57\%) or arrhythmia $(29 \%)$ in the CPR group and pump failure $(38 \%)$ or reinfarction (25\%) in the non-CPR group. At 7 day follow-up the CPR group had a significant increase in ejection fraction $(+5 \pm 9 \%)$ compared with no change in non-CPR group. There were no bleeding complications directly attributed to CPR. In particular, the decrease in hemato-

\footnotetext{
From the Division of Cardiology, Department of Medicine, Duke University Medical Center, Durham, North Carolina; Riverside Methodist Hospital, Columbus, Ohio; Christ Hospital, Cincinnati, Ohio; Division of Cardiology, Department of Internal Medicine, University of Michigan Medical Center, Ann Arbor, Michigan. This work was supported in part by Genentech, Inc., South San Francisco, California, and Abbott Laboratories, Chicago, Illinois, and by Research Grants HS-05635 and HS-06503 from the Agency for IIealth Care Policy and Research, Rockville, Maryland, Research Grants HL-36587 and HL-17670 from the National Heart, Lung, and Blood Institute, Bethesda, Maryland, and a grant from the Robert Wood Johnson Foundation, Princeton, New Jersey. Manuscript received March 21, 1991; revised manuscript received June 5, 1991, and accepted June 6 .

Address for reprints: Robert M. Califf, MD, Box 31123, Duke University Medical Center, Durham, North Carolina 27710.
}

crit (median 11) and need for transfusion (37 vs $32 \%$ ) were the same in both groups. In addition, the CPR group did not spend more days in the cardiac care unit or in hospital than the non-CPR group.

In conclusion, patients who have received CPR for $<10$ minutes had no additional complications attributable to thrombolytic therapy (95\% confidence interval 0 to $5 \%$ ). Therefore, CPR, especially of short duration, should not be considered a contraindication to lytic treatment. In addition, our results suggest that patients requiring CPR during acute infarction constitute a high-risk subgroup which may particularly benefit from receiving thrombolytic therapy.

(Am J Cardiol 1991;68:1015-1019)

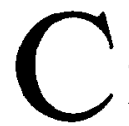

ardiopulmonary resuscitation (CPR) is often citcd as a contraindication to thrombolytic therapy. ${ }^{1,2}$ In patients with acute myocardial infarction the need for defibrillation, prccordial thump, and a short period of chest compression is common, with the reported incidence of early cardiac arrest in clinical trials of thrombolytic therapy ranging from 10 to $16 \%{ }^{3-5}$ The recommendation to exclude such patients from receiving therapy is not based on firm data and no studies that specifically address this question have been published. Because patients requiring CPR are at high risk with conservative therapy, ${ }^{6}$ they potentially have the most to gain from thrombolytic treatment and therefore should not be excluded without good reason. To investigate this issue, we evaluated patients enrolled in the Thrombolysis and Angioplasty in Myocardial Infarction trials who had received CPR before or early in the course of therapy compared with patients who had not received CPR.

\section{METHODS}

The study population included 708 consecutive patients entered into the first 3 Thrombolysis and Angioplasty in Myocardial Infarction trials. ${ }^{7-9}$ Patients presenting within 6 hours of the onset of chest pain with electrocardiographic changes consistent with an acute myocardial infarction ( $>1 \mathrm{~mm}$ ST elevation in 2 contiguous leads) were eligible for study. Exclusion criteria 


\begin{tabular}{|c|c|c|c|}
\hline & $\begin{array}{l}\text { All } \\
\text { CPR } \\
(n=59)\end{array}$ & $\begin{array}{l}\text { Prolonged } \\
\text { CPR } \\
(\mathrm{n}=22)\end{array}$ & $\begin{array}{l}\text { No } \\
\text { CPR } \\
(n=649)\end{array}$ \\
\hline Age (years) & $55(46-60)$ & $58(45-61)$ & $57(49-65)$ \\
\hline Gender: $m / f$ & $47(80) / 12(20)$ & $18(82) / 4(18)$ & $518(80) / 131(20)$ \\
\hline \multicolumn{4}{|l|}{ Race } \\
\hline White & $52(88)$ & $20(91)$ & $602(93)$ \\
\hline Black & $5(8)$ & $2(9)$ & $38(6)$ \\
\hline Indian & $1(2)$ & $O(0)$ & $4(1)$ \\
\hline Asiatic & $1(2)$ & $0(0)$ & $0(0)$ \\
\hline Other & $0(0)$ & $0(0)$ & $5(1)$ \\
\hline \multicolumn{4}{|l|}{ Risk factors } \\
\hline Hypertension* & $29(49)$ & $12(55)$ & $261(40)$ \\
\hline Diabetes mellitus & $11(19)$ & $6(27)$ & $95(15)$ \\
\hline Hyperlipidemia $†$ & $9(15)$ & $4(18)$ & $67(10)$ \\
\hline Cigarette smoking & $46(78)$ & $12(55)$ & $488(75)$ \\
\hline Family history of coronary disease & $31(53)$ & $8(36)$ & $288(44)$ \\
\hline Time to treatment (min) & $160(136-210)$ & $151(131-191)$ & $175(126-220)$ \\
\hline $\begin{array}{l}\text { *Hyertension defined as any previous history of } \\
\text { tHyperlipidemiaia defined as a history of hyperlipid } \\
\text { Values in parentheses indicate percentage except } \\
C P R=\text { cardiopulmonary resuscitation. }\end{array}$ & $\begin{array}{l}\text { osed by a physician } \\
\text { a physician or a hist } \\
\text { treatment where the }\end{array}$ & $\begin{array}{l}\text { edications, diet or exe } \\
\text { esterol }>200 \mathrm{mg} / \mathrm{dl} \text {. } \\
75 \text { th percentiles. }\end{array}$ & \\
\hline
\end{tabular}

were age $>75$ years, history of recent stroke, surgery or trauma, predisposition for bleeding, uncontrolled hypertension (diastolic blood pressure $>120 \mathrm{~mm} \mathrm{Hg}$ ), previous coronary artery bypass surgery, previous Q-wave infarction in the same vascular distribution and cardiogenic shock (systolic blood pressure $<85 \mathrm{~mm} \mathrm{Hg}$ unresponsive to administration of fluid). In addition, CPR for $>10$ minutes was an exclusion criterion. Of the total population of 708 patients, 59 required CPR for $<10$ minutes before receiving lytic therapy or had CPR during or soon after lytic therapy was started ( $<6$ hours). These patients constitute the subpopulation studied.

In phase 1 of the Thrombolysis and Angioplasty in Myocardial Infarction trials, ${ }^{7}$ patients received $150 \mathrm{mg}$ of intravenous tissue plasminogen activator over 6 to 8 hours. Cardiac catheterization was performed 90 minutes after initiation of lytic therapy, with $5,000 \mathrm{U}$ of intravenous heparin administered after arterial access was attained. Patients with patent arteries amenable to angioplasty were then randomized to immediate versus elective angioplasty 7 to 10 days later. Patients with occluded arteries underwent immediate angioplasty in an attempt to restore patency. Repeat catheterization was performed in all patients at 7 days.

In phase $2,{ }^{8}$ patients were treated with 1 of 5 regimens combining various doses of intravenous tissue plasminogen activator $(1 \mathrm{mg} / \mathrm{kg}$ or $25 \mathrm{mg}$ ) and urokinase ( 0.5 to 2.0 million $U)$. Patients were otherwise treated as in phase 1 except that acute angioplasty was only performed for occluded vessels.

In phase $3,{ }^{9}$ patients were randomized to receive either a combination of tissue plasminogen activator (1.5 $\mathrm{mg} / \mathrm{kg}$ over 4 hours) with $10,000 \mathrm{U}$ of heparin or tissue plasminogen activator alone. Otherwise treatment was the same as in phase 2 .
After thrombolytic therapy all patients had similar management, which included the use of anticoagulation with heparin to maintain the activated partial thromboplastin time 1.5 to 2.0 times the control level for $\geq 24$ hours, aspirin $325 \mathrm{mg} /$ day, $1 \mathrm{mg} / \mathrm{kg}$ bolus dose of lidocaine or a $225 \mathrm{mg}$ loading dose followed by 2 to 4 $\mathrm{mg} / \mathrm{min}$ for the first 24 hours, and diltiazem 30 to 90 $\mathrm{mg}$ every 6 to 8 hours. The use of nitroglycerin was at the discretion of the investigator, whereas the use of $\beta$ blockers was prohibited unless specifically required to treat supraventricular tachycardia, hypertension or angina.

CPR was defined as an intervention performed in response to a change in rhythm to ventricular fibrillation, ventricular tachycardia with hemodynamic instability, asystole, or electromechanical dissociation, and included precordial thump, cardioversion or defibrillation, or chest compressions. Because many patients only required 1 or 2 defibrillations, data for patients requiring more extensive CPR than defibrillation only were analyzed separately (prolonged CPR group). Treatment with antiarrhythmic or vasopressor medications alone was not included.

Baseline characteristics and clinical outcomes were collected prospectively by trained research nurses using previously described definitions. ${ }^{7-9}$ General bleeding complications were similarly characterized. Data on days in the cardiac care unit and total days hospitalized are not available for patients in phase 1 . All routinely collected variables were verified by primary source documentation by a second trained nurse. Specific details and complications of CPR were collected retrospectively by the same research nurses on supplemental data forms. In some patients initially seen in small community hospitals, details of CPR are incomplete. 


\begin{tabular}{|lc|}
\hline TABLE II Details of Cardiopulmonary & Resuscitation $(n=59)$ \\
\hline & No. of \\
& Pts. (\%) \\
\hline Reason for CPR & \\
Ventricular fibrillation & $43(73)$ \\
Ventricular tachycardia & $14(24)$ \\
Asystole & $1(2)$ \\
Electromechanical dissociation & $1(2)$ \\
Number of cardioversions/defibrillations & $2(1-3)$ \\
Median (25th-75th percentiles) & \\
Maximal energy delivered (J) & $300(200-360)$ \\
Median (25th-75th percentiles) & \\
Precordial thump & $10(17)$ \\
Yes & $36(61)$ \\
No & $13(22)$ \\
Unknown & \\
Chest compression & $23(39)$ \\
Yes & $26(44)$ \\
No & $10(17)$ \\
Unknown & \\
Timing of CPR & $50(85)$ \\
Before thrombolytics & $7(12)$ \\
During thrombolytics & $2(3)$ \\
After thrombolytics & $1(1-5)$ \\
Duration of CPR (min) & \\
Median (25th-75th percentiles) & \\
\hline Numbers in parentheses indicate percentages unless otherwise specified. \\
CPR = cardiopulmonary resuscitation. \\
\hline
\end{tabular}

All data are described with either percentiles for continuous variables or percentages for discrete variables, except for ejection fraction which is expressed as mean \pm standard deviation. The Wilcoxon rank-sum test was used to test comparisons for continuous variables, whereas discrete data were analyzed using Fisher's exact test or the chi-square test. A p value $<0.05$ was considered statistically significant.

\section{RESULTS}

Of 708 patients entered into the trials, 59 (8\%) had a cardiac arrest. Thirty-seven of these patients required only defibrillation and 22 required more extensive resuscitation (prolonged CPR group). There were no significant differences between the CPR and non-CPR groups in many baseline characteristics including gender, the presence of risk factors for coronary artery disease or time until treatment (Table I). The CPR group was slightly younger and had slightly fewer white patients. The subpopulation of patients with prolonged CPR was also similar to the control population in baseline characteristics. Details of CPR are listed in Table II.

Patients who received CPR were more likely to have an anterior myocardial infarction (66 vs $39 \%$ ) and to have left anterior descending artery as the infarct-related artery (63 vs $38 \%$ ) (Table III). There were no significant differences in the number of diseased vessels, infarct vessel patency as assessed by Thrombolysis in Myocardial Infarction flow grade, or in the percentage

\begin{tabular}{|lccc|}
\hline TABLE III Initial Catheterization Results \\
\hline \multicolumn{4}{c|}{ All CPR } \\
$(n=59)$ & $\begin{array}{l}\text { Prolonged CPR } \\
(n=22)\end{array}$ & No CPR \\
$(n=649)$
\end{tabular}

\begin{tabular}{|lll|}
\hline TABLE IV Mortality & \multicolumn{2}{l|}{} \\
\hline & $\begin{array}{l}\text { All CPR } \\
(n=59)\end{array}$ & $\begin{array}{l}\text { No CPR } \\
(n=649)\end{array}$ \\
\hline Mortality & $7(12)$ & $40(6)$ \\
Death day 1 & $4(57)$ & $11(28)$ \\
Death day 2-7 & $0(0)$ & $16(40)$ \\
Death day $>7$ & $3(43)$ & $13(33)$ \\
Cause of death & & \\
Pump failure & $4(57)$ & $15(38)$ \\
Arrnythmia & $2(29)$ & $2(05)$ \\
Reinfarction & $0(0)$ & $10(25)$ \\
Infection & $1(14)$ & $2(05)$ \\
Stroke & $0(0)$ & $2(05)$ \\
Cardiac rupture & $0(0)$ & $2(05)$ \\
Respiratory failure & $0(0)$ & $2(05)$ \\
Unknown & $0(0)$ & $5(13)$ \\
\hline Except for the first line, numbers in parentheses indicate percentages calculated \\
from the number of patients who died \\
CPR = cardiopulmonary resuscitation.
\end{tabular}

of patients treated with acute angioplasty. The patients with prolonged CPR also had a preponderance of anterior infarctions $(77 \%)$ and left anterior descending artery lesions $(74 \%)$. The baseline ejection fraction was lower in the CPR group as expected, given the greater proportion of anterior infarcts.

The in-hospital mortality was somewhat higher in the CPR group, and the prolonged CPR group had a higher mortality rate than the non-CPR group ( 32 vs 


\begin{tabular}{|c|c|c|c|}
\hline & $\begin{array}{l}\text { All CPR } \\
(n=59)\end{array}$ & $\begin{array}{l}\text { Prolonged CPR } \\
(n=22)\end{array}$ & $\begin{array}{l}\text { No CPR } \\
(n=649)\end{array}$ \\
\hline Reocclusion & $6(11)$ & $3(17)$ & $79(13)$ \\
\hline Subsequent cardiac arrest* & $8(14)$ & $5(23) \dagger$ & $51(08)$ \\
\hline Sustained hypotension & $13(22)$ & $8(36) \dagger$ & $102(16)$ \\
\hline Pulmonary edema & $15(25) \ddagger$ & $7(32) \dagger$ & $73(11)$ \\
\hline Congestive heart failure & $10(17)$ & $3(14)$ & $68(11)$ \\
\hline Stroke & $0(0)$ & $0(0)$ & $13(2)$ \\
\hline Coma & $4(07)$ & $4(18) \dagger$ & $13(2)$ \\
\hline Change in ejection fraction§ & $\begin{array}{l}+5 \pm 9 \neq \\
(n=33)\end{array}$ & $\begin{array}{l}+4 \pm 8 \\
(n=10)\end{array}$ & $\begin{array}{l}0 \pm 9 \\
(n=444)\end{array}$ \\
\hline \multicolumn{4}{|c|}{$\begin{array}{l}\text { *CPR atter admission to the hospital. } \\
\text { tp value }<0.05 \text { between prodonged CPR and no CPR. } \\
\text { tpvalue }<0.05 \text { between all CPR and no CPR. } \\
\text { SPatients with repeat ventriculogram before discharge. } \\
\text { CPR = cardiopulmonary resuscitation. }\end{array}$} \\
\hline
\end{tabular}

$6 \%, p=0.0001$ ). All of the deaths in the CPR group occurred in the group with prolonged CPR. In both groups, many of the deaths occurred during the first hospital day (Table IV). The most common cause of death in both groups was pump failure.

The hospital course in the total CPR and non-CPR groups was similar with respect to reocclusion, subsequent cardiac arrest, sustained hypotension, congestive heart failure, stroke or coma (Table V). The prolonged CPR group had a greater incidence of subsequent cardiac arrests, sustained hypotension, pulmonary edema and coma. Both the total CPR and prolonged CPR groups had an increase in ejection fraction on the predischarge ventriculogram ( 5 and $4 \%$, respectively) compared with no increase in the non-CPR group.

There were no direct complications of CPR noted. Specifically, there were no cases of pericardial tamponade, rib or sternal fractures, pneumo- or hydrothorax, lung contusion, organ rupture or laceration, or embolic events attributable to CPR. The rate of bleeding complications was the same in both groups with regard to all parameters evaluated (median decrease in hematocrit, lowest hematocrit, and units of red blood cells transfused were 11,31 , and 0 in the CPR group vs 11 , 32 and 0 in the non-CPR group). Both groups also had a similar number of days in the cardiac care unit (median 3) and total days hospitalized (median 9).

\section{DIsCUSSION}

In 1980, a National Institutes of Health Consensus Development Conference on Thrombolytic Therapy ${ }^{1}$ suggested that CPR was a relative contraindication to thrombolytic therapy. More recently the American College of Cardiology/American Heart Association guidelines for treatment of acute myocardial infarction also listed CPR as a relative contraindication. ${ }^{2}$ Most of the major clinical trials have excluded such patients. $3,4,10-13$ This question has a substantial practical value given the large number of patients who may be unnecessarily excluded from receiving the optimal treatment for their myocardial infarction. In our study, we found that $8 \%$ of the patients required some form of resuscitation, while another large series found a figure of $16 \% .^{3}$

In 2 large studies cardiac arrest occurred in $10 \% 4$ and $11 \%$ of patients treated with thrombolytic therapy, although the use of CPR was not specified and the outcome in these patients was not discussed separately. One very early study of urokinase did report outcomes separately in patients who had sustained cardiac arrest: 0 of 3 patients who had cardiac arrest before urokinase treatment died compared with 3 of 14 without cardiac arrest. ${ }^{14}$ One large study with data on this question is the Gruppo Italiano per lo Studio della Streptochinasi Nell'Infarto Miocardico I study, which reported separate data for the $3 \%$ of that population of 11,712 patients who had primary ventricular fibrillation. Patients with ventricular fibrillation who received streptokinase had a mortality of $9 \%$ compared with $12 \%$ in similar patients who did not receive treatment. ${ }^{15}$

In our study, the group who received CPR did not differ significantly from the remainder of our patients except for a predominance of anterior myocardial infarctions. As expected, the ejection fraction at the baseline catheterization was lower in the CPR group. It is not surprising that those with larger infarcts were more likely to sustain cardiac arrest and that mortality would be higher in the group requiring CPR. However, the significant improvement in ejection fraction seen at 7day follow-up in the CPR group compared with no improvement in the non-CPR group is an important finding. Although the increase in ejection fraction could represent recovery from cardiac depression resulting from CPR itself, this finding suggests that thrombolytic therapy may be particularly beneficial in this high-risk subgroup. We found no direct complications due to CPR, and in-hospital adverse events, bleeding complications and length of hospital stay were similar in the 2 groups.

The potential limitations of this study are important to recognize. First, our study population excluded patients with CPR of $>10$ minutes and therefore no conclusion can be made for that group of patients. However, the mortality for patients requiring very prolonged CPR is extremely high. One study found only $5 \%$ survival in a general population of hospitalized patients requiring $>15$ minutes of resuscitation. ${ }^{16}$ Therefore, in such a group the additional risk of thrombolytic therapy would be very small and the potential benefit large.

Second, there is potential of $\beta$ error to the extent that if more patients were studied we would have found 
more complications attributable to CPR. However, the $95 \%$ confidence interval for no complications is 0 to $5 \%$ overall and 0 to $14 \%$ for patients with prolonged CPR.

Third, we do not have data on patients who were eligible but not entered into the trials. There may have been a selection bias so that patients with complications from CPR were not given thrombolytic therapy. However, our conclusions should remain valid for patients with apparently uncomplicated CPR.

Finally, it may be argued that this is a retrospective study and that only a prospective study randomizing patients who have received CPR to thrombolytics or no thrombolytics will be able to fully resolve the issue. Although we do not have data in this study for patients who received CPR and did not get thrombolytics, it is possible that the potential benefit of therapy in this group is even greater than for the total population of patients with infarction. A previous study found $66 \%$ mortality in patients who had cardiac arrest early in the course of myocardial infarction compared with $4 \%$ in patients without such a complication. ${ }^{6}$ In addition, the limited data from the Gruppo Italiano per lo Studio della Streptochinasi Nell'Infarto Miocardico trial also showed a benefit of thrombolytic therapy in patients with cardiac arrest due to ventricular fibrillation. ${ }^{15}$

In conclusion, this study found no adverse effect in giving thrombolytic therapy to patients requiring a short duration of CPR, suggesting that these patients should not be excluded from this form of treatment.

\section{REFERENCES}

1. Sherry S, Bell WR, Duckert FH, Fletcher AP, Gurewich V, Long DM, Marder VJ, Roberts H, Salzman EW, Sasahara A, Verstraete M. Thrombolytic therapy in thrombosis: a National Institutes of Health Consensus Development Conference. Ann Intern Med 1980;93:141-144.
2. Gunnar RM, Passamani ER, Bourdillon PDV, Pitt B, Dixon DW, Rapaport E, Fuster V, Reeves TJ, Karp RB, Russell RO Jr, Kennedy JW, Sobel BE, Klocke FJ, Winters WL Jr. Guidelines for the early management of patients with acute myocardial infarction. J Am Coll Cardiol 1990;16:249-292.

3. Wilcox RG, Olsson CG, Skene AM, von der Lippe G, Jensen G, Hamptom JR. Trial of tissue plasminogen activator for mortality reduction in acute myocardial infarction. Lancet 1988;2:525-530.

4. O'Rourke M, Baron D, Keogh A, Kelly R, Nelson G, Barnes C, Raftos J, Graham K, Hillman K, Newman H, Healey J, Woolridge J, Rivers J, White H, Whitlock R, Norris R. Limitation of myocardial infarction by early infusion of recombinant tissuc-type plasminogen activator. Circulation 1988;77:1311-1315. 5. Kennedy JW, Ritchie JL, Davis KB, Fritz JK. Western Washington randomized trial of intracoronary streptokinase in acute myocardial infarction. $N$ Engl $J$ Med 1983;309:1477-1482.

6. Goldberg RJ, Gore JM, Haffajee CI, Alpert JS, Dalen JE. Outcome after cardiac arrest during acute myocardial infarction. Am J Cardiol 1987; 59:251-255.

7. Topol EJ, Califf RM, George BS, Kereiakes DJ, Abbottsmith CW, Candela RJ, Lee KL, Pitt B, Stack RS, O'Neill WW. A randomized trial of immediate versus delayed elective angioplasty after intravenous tissue plasminogen activator in acute myocardial infarction. $N$ Engl J Med 1987;317:581-588.

8. Topol EJ, Califf RM, George BS, Kereiakes DJ, Rothbaum D, Candela RJ, Abbottsmith CW, Pinkerton CA, Stump DC, Collen D, Lee KL, Pitt B, Kline EM, Boswick JM, O'Neill WW, Stack RS. Coronary arterial thrombolysis with combined infusion of recombinant tissue-type plasminogen activator and urokinase in patients with acute myocardial infarction. Circulation 1988;77: $1100-1107$.

9. Topnl EJ, George BS, Kereiakes DJ, Stump DC, Candela RJ, Abbottsmith CW, Aronson L, Pickel A, Boswick JM, Lee KL, Ellis SG, Califf RM. A randomized controlled trial of intravenous tissue plasminogen activator and early intravenous heparin in acute myocardial infarction. Circulation 1989;79:281 286. 10. The TIMI Study Group. The Thrombolysis in Myocardial Infarction trial. $N$ Engl J Med 1985;312:932-936.

11. Gruppo Italiano Per Lo Studio Della Streptochinasi Nell'Infarto Miocardicu. Effectiveness of intravenous thrombolytic treatment in acute myocardial infarction. Lancet 1986;1:397-401.

12. ISIS Pilot Study Investigators. Randomized factorial trial of high-dose intravenous streptokinase, of oral aspirin and of intravenous heparin in acute myocardial infarction. Eur Heart $J$ 1987;8:634-642.

13. The TIMI Study Group. Comparison of invasive and conservative strategies after treatment with intravenous tissue plasminogen activator in acute myocardial infarction. $N$ Engl J Med 1989;320:618-627.

14. Litman GI, Stniley RB Jr, Wenger NK. The feasibility of urokinase therapy in acute myocardial infarction. Am J Cardiol 1971;27:636-640.

15. Volpi A, Maggioni A, Franzosi MG, Pampallona S, Mauri F, Tognoni G. Inhospital prognosis of patients with acute myocardial infarction complicated by primary ventricular fibrillation. $N$ Engl J Med 1987;317:257-261.

16. Bedell SE, Delbanco TL, Cook EF, Epstein FH. Survival after cardiopulmonary resuscitation in the hospital. $N$ Engl J Med 1983;309:569-576. 